\title{
The assessment of the series active filter efficiency in power supply systems of oil production enterprises
}

\author{
Yuriy Sychev ${ }^{1, *}$, Roman Zimin ${ }^{1}$, Maxim Aladin ${ }^{1}$ \\ ${ }^{1}$ Electromechanical Department, Saint-Petersburg Mining University (SPMU), 199106, Saint-Petersburg, Russia
}

\begin{abstract}
This paper deals with the problem of the efficient application of the series active filter in conditions of power supply systems of oil production enterprises with non-linear load and voltage dips. The mathematical model of the power supply system of oil production enterprise with the connected series active filter is developed. The control system for the series active filter with usage of the phase transformations, symmetrical components and frequency-controlled pulse-width modulation of IGBT control pulses is developed and proved. Based on the modelling results, the analysis of the efficiency of power quality indicators' correction by means of the series active filter is carried out. The dependence of the voltage total harmonic distortion factor from the rated power of the output transformer of the series active filter is obtained.
\end{abstract}

\section{Introduction}

The modern power supply systems of oil production enterprises possess three main features. The first is the wide spread of non-linear loads such as the power frequency converters, which are intended for the control of the submersible electric motors of the technological electrocentrifugal pumps of the oil production wells [1, 2]. The second is the significant length of power lines from the source to the consumer. The third is the presence of voltage dips and deviations whose origin may be caused by the failures in the centralized power supply systems and by the connection of the fast-variable load such as the drilling installations. All these features are connected with the power quality indicators of the network voltage, which influence on the stable and reliable work of the technological installations. That is why the problem of the voltage power quality indicators correction is quite actual [3]. Also it should be noted that the complex application of the distributed generation technologies both separately and jointly with centralized power supply influences on the voltage parameters and characteristics [4].

Nowadays there is the set of the national and international standards and rules in the area of voltage power quality. For example the standard EN 50160:2010 is valid in the European Union, the United States accepted the power quality standard IEEE 1159-2009, in Russian Federation the standard of power quality in general purpose power supply systems GOST 321442013 came into force on inter-state level from July 1, 2014 [5, 6]. The electrical equipment of oil industry is designed and operated in accordance with applicable rules and regulations, including standards in the field of power quality adopted at the state level [7, 8].

On the basis of the results of the complex analysis of the above mentioned standards regarding comparison of the voltage power quality indicators, in practice it is possible to apply a number of the technical devices and solutions intended to increase the technological and electrotechnical equipment efficiency, considering the main features and specifics of the oil production enterprises at the improvement of the reliability and stability indicators and positive dynamics of all production development $[9,10]$. For example according to the results of theoretical and experimental researches [11] for the submersible electric motors of the technological electrocentrifugal pumps of the oil production wells the permissible duration of the power supply interruptions is detected, which equals to $0.15 \mathrm{~s}$. Figure 1 shows the dependences of the permissible voltage dip $\Delta U_{d}$ level (in p.u., where the basis value is the rated voltage), which ensures the required degree of dynamic stability of the submersible electric motors regardless of the voltage dip duration, from the submersible motor placement depth $(L)$ and power utilization factor $\left(k_{u}\right)[11,12]$.

\footnotetext{
*Corresponding author: sychev_yura@mail.ru
} 


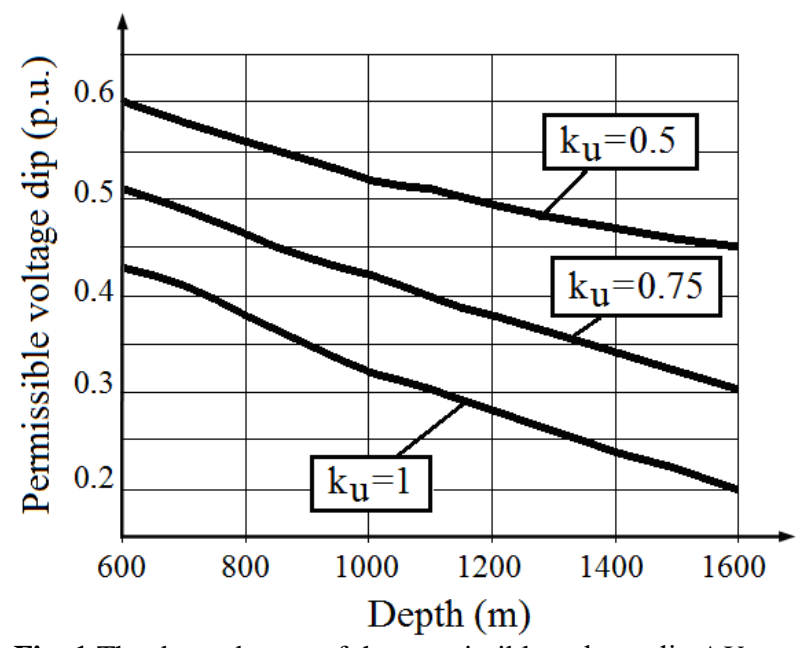

Fig. 1 The dependences of the permissible voltage dip $\Delta U_{d}$ level (in p.u.) from the submersible motor placement depth $(L)$ and power utilization factor $(k u)$.

These dependences show that the correction of the voltage dips and deviations is necessary for the ensuring of the stability and continuity of the oil production technological process.

When we connect the powerful load to some point of the long power line, such as the drilling installation which working mode is not constant but fast-variable, we may have the voltage dips of the significant level in the line end, where the important load may be connected from the technological point of view.

Also the presence of current harmonics from the connected non-linear load leads to the voltage distortion in the whole power supply system. This phenomenon causes the current distortions in the linear loads, which may destroy them [13].

That is why in such conditions we should consider the multifunctional active devises which are able to correct several voltage quality indicators simultaneously.

\section{Methods}

There are two main types of the active filters: shunt and series active filters.
The first type is intended for current harmonics and asymmetry correction. It is a controllable current source on the basis of voltage or current source inverter with the output passive filter $[14,15]$. In some cases such active filter can correct power factor by means of the elimination of the reactive current component. The proper implementation of all indicated functions is determined by the algorithm of the filters' control system. The classic shunt active filter is not able to eliminate voltage dips, deviations, asymmetry and harmonics, which occur from the power source side. Such filter type is connected in parallel with non-linear load or load node, which includes a part of non-linear consumers and a part of linear consumers.

The second type is intended for voltage dips, deviations, asymmetry and harmonics correction. The series active filter is also may be called the dynamic voltage restorer (DVR). Such filter is a controllable voltage source also on the basis of voltage or current source inverter with the output passive filter and transformer [16]. The proper implementation of all indicated functions is also determined by the algorithm of the filter control system. Similarly to the previous case the classic series active filter is not able to eliminate current asymmetry and harmonics, which occur from the load node side.

As you may see such active filters should be considered as a multifunctional device with the control system, which can implement all demanded purposes with the set efficiency level. The control system of active filters should be based on the phase transformations (Clarke transformations), the symmetrical components transformation (Fortescue transformations), the phase locked loop system (PLL), the relay regulators with the variable width of hysteresis, the variable pulse-width modulation (PWM) frequency $[17,18]$.

The proposed control system for the series active filter is implemented on the PLL system with the detection of the fundamental network voltage component in the power supply system, as shown in Figure 2.

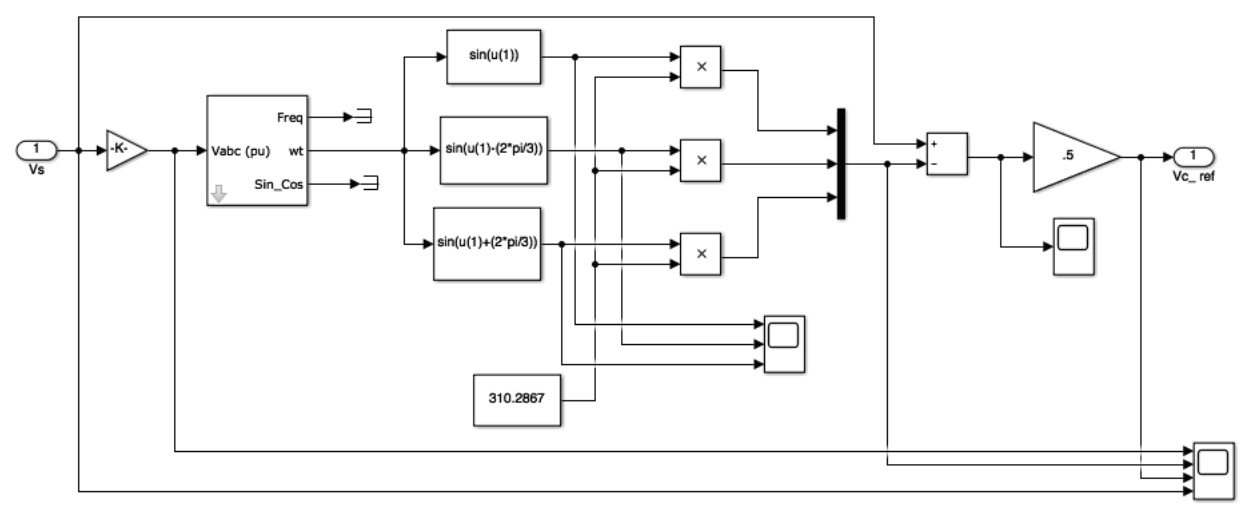

Fig. 2 The proposed control system for the series active filter in Matlab Simulink software

The proposed control system includes the PLL unit without phase transformations, the reference voltage value identification block and the pulse generation module, whose output signals are fed to the inverter [19].
The PLL system realizes the function of the detection of the reference sine-wave unit signal, which is used further for the determination of the reference voltages [3]. 
The reference voltage value identification block implements the determination of the reference values of phase network voltages. The direct sequence of the network phase voltage component can be calculated as follows [13]:

$$
u_{a}^{+}=\frac{1}{\sqrt{3}}\left(u_{a}+a u_{b}+a^{2} u_{c}\right)
$$

In equation (1) $u_{a}, u_{b}, u_{c}$ - phase voltages, $a$ is the operator defined as $a=e^{j 2 \pi / 3}$, which involves a phase shift of 120 electrical degrees [13].

After application (1), the inverse transformation is performed to obtain the desired voltage vector [13]. The calculation is performed using the following equation [13]:

$$
\overrightarrow{\mathbf{u}}_{+}=\left[\begin{array}{lll}
u_{a}^{+} & u_{b}^{+} & u_{c}^{+}
\end{array}\right]^{T}=\frac{1}{\sqrt{3}}\left[\begin{array}{lll}
u_{a}^{+} & u_{a}^{+} & u_{c}^{+}
\end{array}\right]^{T}
$$

In equation (2) $u_{a}^{+}, u_{b}^{+}, u_{c}^{+}$are the components of the direct sequence of the voltage vector of each phase [13].

The pulse generation module is implemented on the base of relay regulators with variable hysteresis width, which value defines the PWM frequency of inverter power keys. In this case there is an opportunity to tune the hysteresis width according to the required level of voltage quality indicators correction and the acceptable termal mode of inverter power keys [19].

Also for voltage harmonic compensation in practical application, a discrete PWM control circuit is implemented. The function of such circuit is to support a constant voltage at the sensitive load point when changing the structure of the power supply system [20, 21]. The control circuit measures only the RMS voltage at the sensitive load point, but reactive power measurement is not required for control of the active filter keys [22].

The PWM signal is a rectangular 10 volt pulse wave where each pulse varies in duration between $1 \mathrm{~ms}$, interpreted as a full reverse and $2 \mathrm{~ms}$, with a $1.5 \mathrm{~ms}$ pulse midway between two neutral or zero power output indicators. The period of the total PWM signal is about 15-16 ms or about $50 \mathrm{~Hz}$. The control circuit uses a slightly wider pulse, but can be calibrated to use these pulses [16, 23].
While developing the control circuit the assumption was made about the network balance and operating conditions. The modulating angle $\delta$ is applied to the PWM generator in phase $A$, and the phase $B$ and $C$ angles are shifted by $240^{\circ}$ or $-120^{\circ}$ and $120^{\circ}$ respectively $[13,16]$ according to the following equations:

$$
\begin{aligned}
& u_{A}=\sin (\omega t+\delta) \\
& u_{B}=\sin (\omega t+\delta-2 \pi / 3) \\
& u_{C}=\sin (\omega t+\delta+2 \pi / 3)
\end{aligned}
$$

\section{Results and discussion}

The mathematical model of the series active filter with the proposed control system was developed in Matlab Simulink software for the assessment the efficiency level of voltage quality indicators correction. The scheme of the developed model is presented in Figure 3. The parameters of the developed model, including parameters of the power source, load node and power lines were selected according to the results of the experimental researches at the power supply systems of the oil production enterprises [1]. This model includes the following main parts. The source is presented as a centralized power supply system with infinite power, which is connected through a step-down transformer according to the scheme $\mathrm{D} / \mathrm{Yg}$. The non-linear load is connected to the transformer via a $0.5 \mathrm{~km}$ line. Also there is the passive filter of RC type at the output of the active filter to eliminate high-order harmonics. The RC filter is connected according to the Yg scheme [1, 11]. The switching of was carried out from $0.1 \mathrm{~s}$ to $0.3 \mathrm{~s}$. based on the analysis of the voltage spectrogram, it was detected that the voltage total harmonic distortion factor (THDu) decreases from 7.68 to 1.04 . From the analysis of the spectrogram of voltage it follows that the level of power quality after voltage harmonic compensation corresponds to the requirements of GOST 32144-2013.

As the result of modeling, the waveforms and spectrograms of voltage in the power supply system were obtained. Figures 4 and 5 show the voltage waveforms and spectrograms at different times with the series active filter connection. 


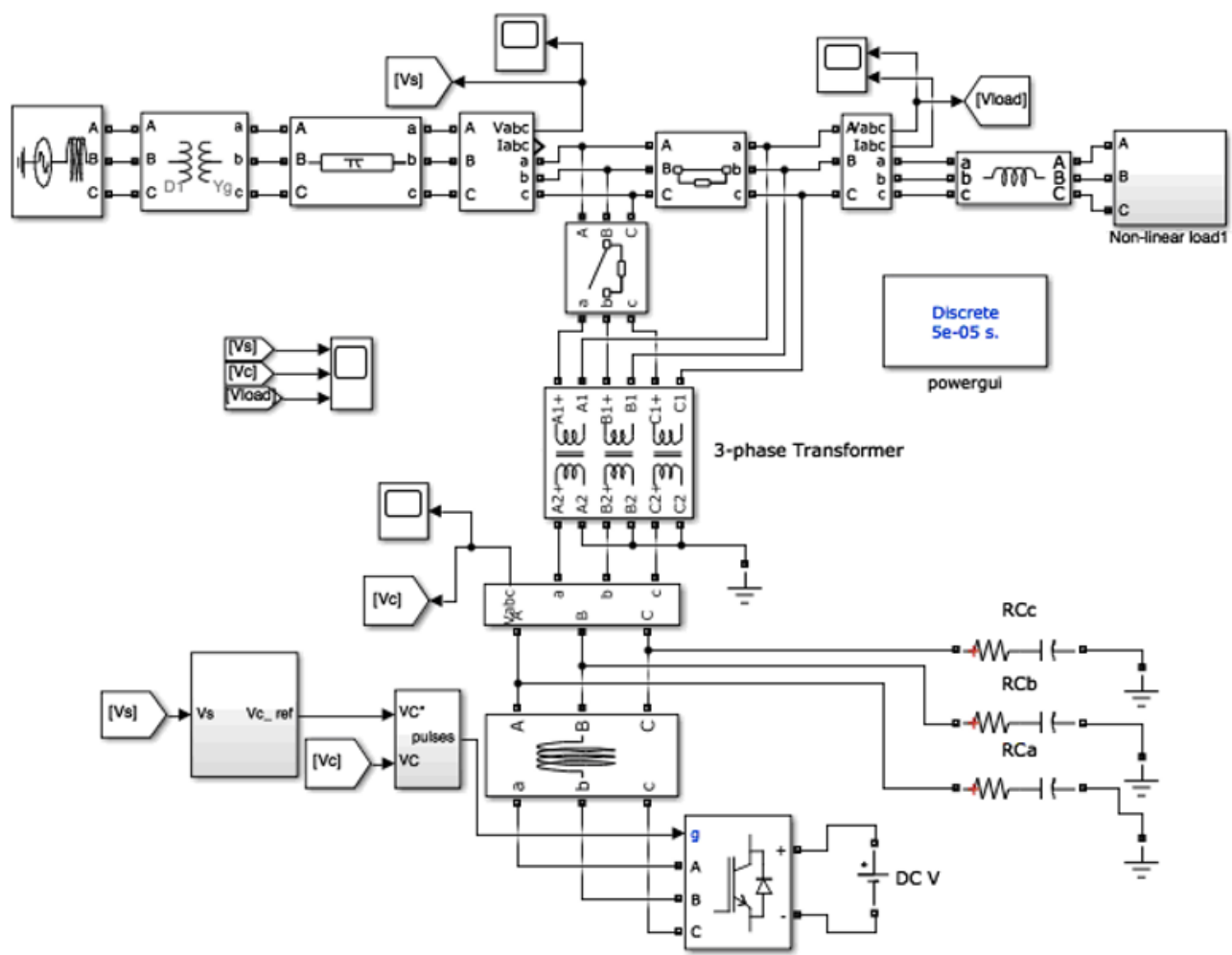

Fig. 3 The mathematical model of the series active filter with the proposed control system
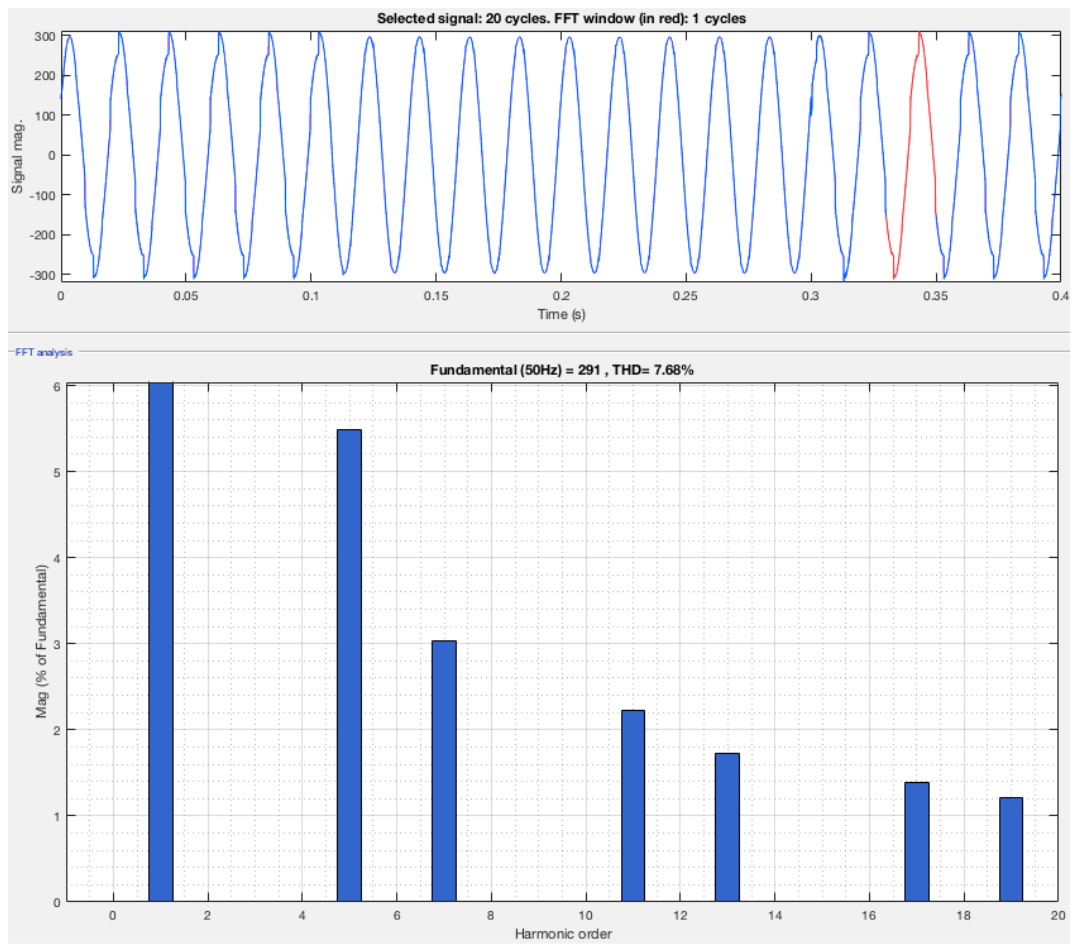

Fig. 4 The waveform and spectrogram of the power supply voltage without filtering 

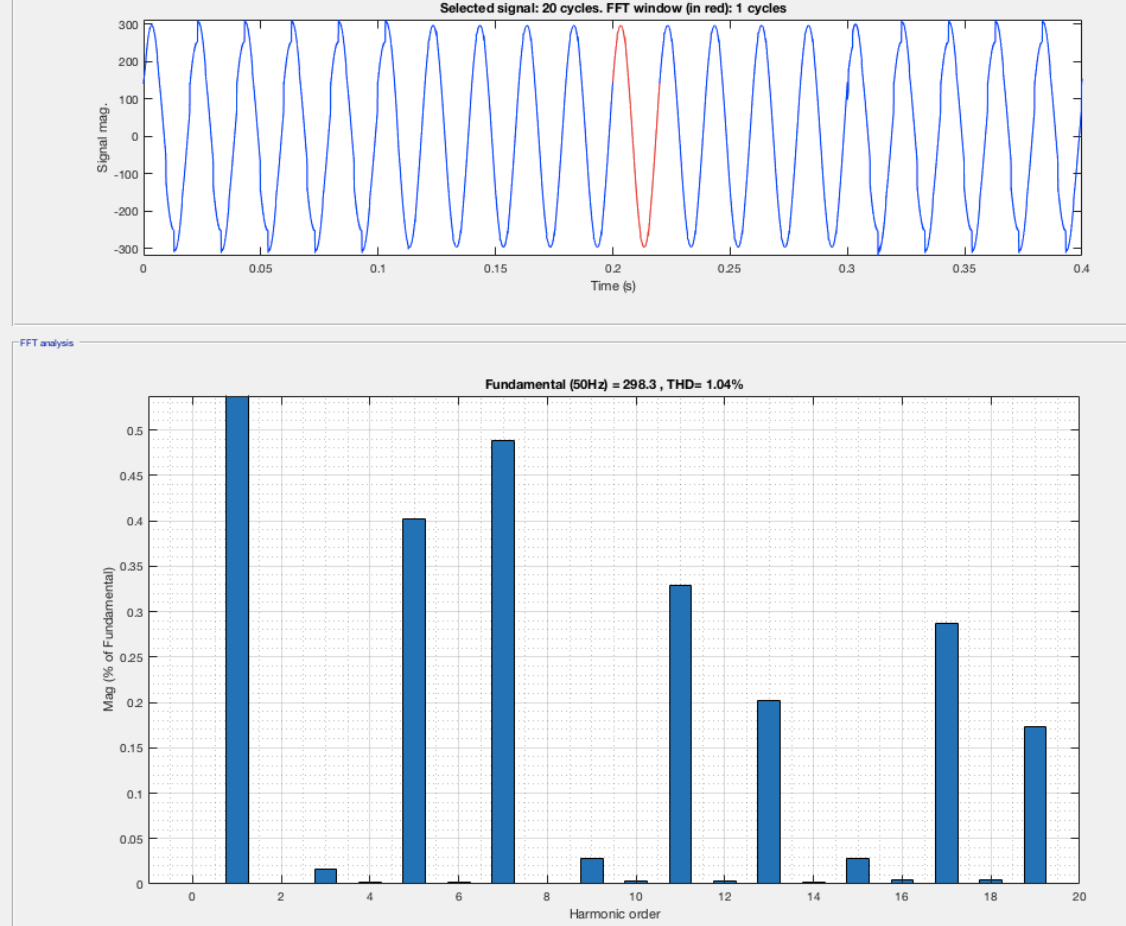

Fig. 5 The waveform and spectrogram of the power supply voltage with the series active filter connection

Figure 6 shows in details the voltage waveform of one phase at the moment of the series active filter connection.

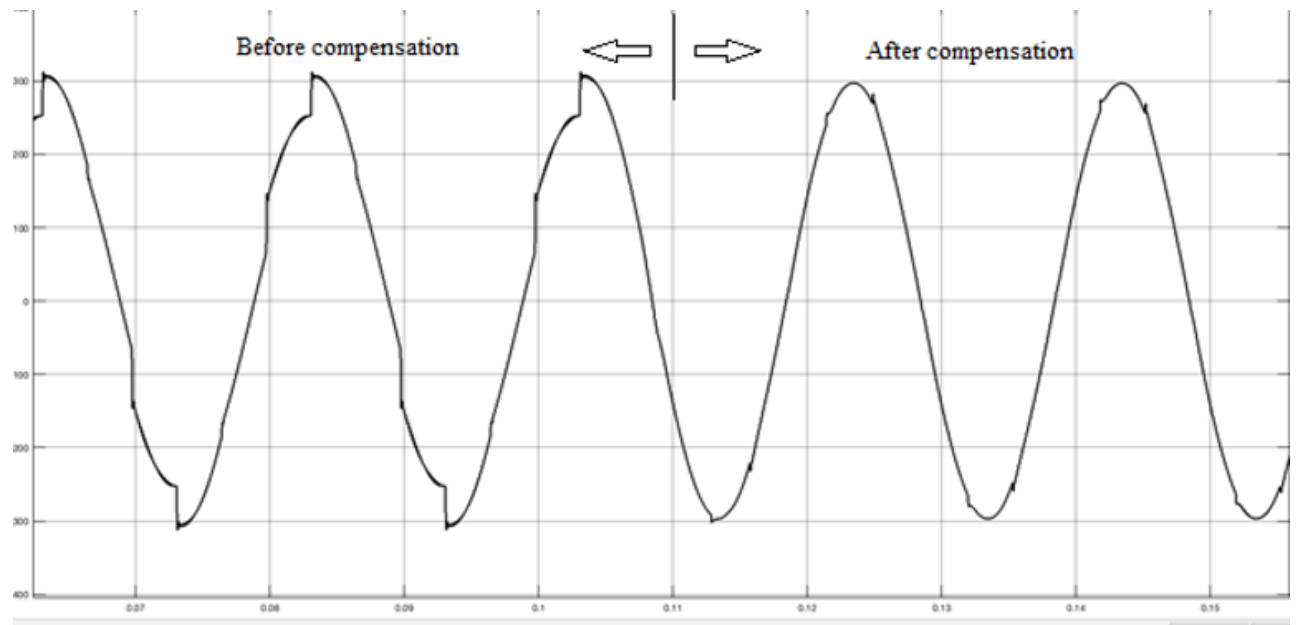

Fig. 6 The moment the series active filter is switched on in the power supply system

During modeling the influence degree of the output transformer rated power $S_{t}$ on the efficiency level of harmonics correction was detected. Figure 7 shows the dependence of the THDu factor from the rated power $S_{t}$ of the output transformer in p.u. where the basis value is the initial level of $S_{t}$, which is calculated for the nominal conditions. Also during modelling the series active filter with the proposed control system ensures the efficient elimination of voltage deviations in the range of 5-10\% from the rated voltage. 


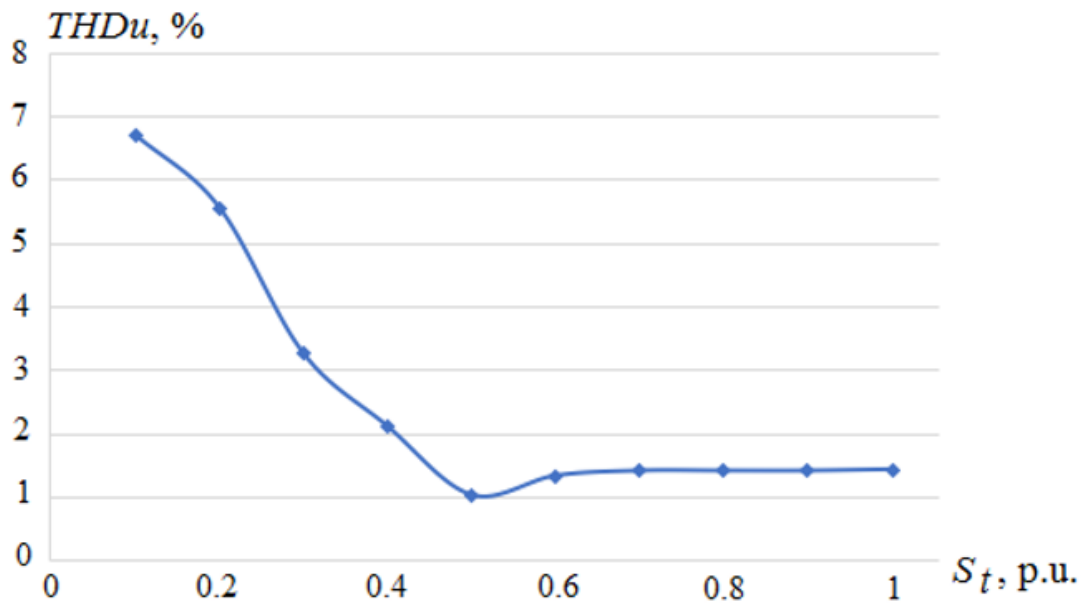

Fig. 7 Dependence of the total voltage harmonic distortion from the power of the active filter transformer

Analysis of the obtained dependence shows that voltage harmonic compensation with the required efficiency level may be achieved when the power of the output transformer is changed in the range of $0.6-1$ from the initial rated value. Thus, this range should be taken into account when application the series active filter as a part of the hybrid filters [14-16].

\section{Conclusion}

The study of the application efficiency of the series active filter in the conditions of the power supply systems of the oil production enterprises is carried out. The main features of the power supply systems of the oil production enterprises are detected in the power quality area. The control system of the series active filter is developed. The mathematical model of the series active filter in the power supply system of oil production enterprise is designed. The obtained modelling results showed the required efficiency level of voltage quality indicators correction by means of the series active filter. The range of the permissible decreasing of the rated power of the series active filter output transformer with saving the required level of voltage harmonic correction is detected for the opportunity to apply such filter as a part hybrid structures.

\section{References}

1. B.N. Abramovich, Y.A. Sychev, R.Y. Zimin, IOP Conf. Ser.: Earth Environ. Sci. 87(3), 032002 (2017)

2. B.N. Abramovich, Y.A. Sychev, Proc. of the Dynamics of Systems, Mechanisms and Machines, Dynamics 2016, 7818962 (2017)

3. V.B. Prokhorova, Y.A. Sychev, 15th International Symposium on Problems of Redundancy in Information and Control Systems, REDUNDANCY 2016, 119-124 (2016)

4. A.A. Belsky, V.S. Dobush, IOP Conf. Ser.: Mater. Sci. Eng. 489(1), 012013 (2019)

5. R.S. Fediuk, A.M. Cherneev, IOP Conf. Ser.: Mater. Sci. Eng. 124(1), 012009 (2016)
6. Y.V. Gulkov, A.V. Turysheva, A.V. Kopteva, Proc. of the 2019 IEEE Conference of Russian Young Researchers in Electrical and Electronic Engineering, ElConRus 2019, 969-972 (2019)

7. V.Y. Frolov, A.A. Neelov, R.I. Zhiligotov, A.V. Bystrov, Proc. of the 2018 IEEE Conference of Russian Young Researchers in Electrical and Electronic Engineering, ElConRus 2018, 626-628 (2018)

8. D.N. Pelenev, B.N. Abramovich, A.V. Turysheva, K.V. Babyr, Proc. of the 2019 IEEE Conference of Russian Young Researchers in Electrical and Electronic Engineering, ElConRus 2019, 1025-1028 (2019)

9. M.S. Kovalchuk, S.V. Baburin, IOP Conference Series: Materials Science and Engineering 327(2), 022065 (2018)

10. S.V. Baburin, M.S. Kovalchuk, Proc. of the 2018 IEEE Conference of Russian Young Researchers in Electrical and Electronic Engineering, ElConRus 2018, 566-569 (2018)

11. B.N. Abramovich, J. of Mining Inst. 229, 31-40 (2018)

12. D.A. Ustinov, Proc. of the 12th International Scientific and Technical Conference "Dynamics of Systems, Mechanisms and Machines", Dynamics 2018, 8601457 (2018)

13. S.P. Litran, P. Salmeron, J. Prieto Alejandro Perez, Proc. of the International Conference on Renewable Energies and Power Quality (ICREPQ’14) 12, 27-33 (2014)

14. $\mathrm{X}$. $\mathrm{Xu}$, Proc. of the 2016 IEEE International Conference on Power and Renewable Energy (ICPRE), 269-274 (2016)

15. A. Jalali, M. Aldeen, Proc. of the 2016 IEEE PES Innovative Smart Grid Technologies Conference Europe (ISGT-Europe), 1-6 (2016)

16. F. Pai, P. Tseng, J. Huang, Proc. of the 2016 IEEE International Conference on Power and Renewable Energy (ICPRE), 172-176 (2016)

17. O. Bolshunova, A. Korzhev, Proc. of the 2nd International Conference on Industrial Engineering, 
Applications and Manufacturing, ICIEAM 2016, 7910928 (2016)

18. M. Baeva, J. Zalach, G. Petrov, V. Frolov, D. Uhrlandt, 19th Symphosium on Physics of Switching Arc 2011, 105-108 (2011)

19. Y.L. Zhukovskiy, N.A. Korolev, I.S. Babanova, A.V. Boikov, IOP Conf. Ser.: Earth Environ. Sci. 87(3), 032056 (2017)

20. A.N. Skamyin, O.S. Vasilkov, 2019 Electric Power Quality and Supply Reliability Conference (PQ) \& 2019 Symposium on Electrical Engineering and Mechatronics (SEEM), 18957601 (2019)

21. V.Y. Frolov, A.V. Bystrov, A.A. Neelov, Proceedings of the 2017 IEEE Russia Section Young Researches in Electrical and Electronic Engineering Conference, ELConRus, 7910686, 83840 (2017)

22. V.Y. Frolov, A.I. Toropchin, Technical Physics Letters 41(7), 635-637 (2015)

23. L.R. Limongi, L.R. Silva Filho, L.G.B. Genu, F. Bradaschia, M.C. Cavalcanti, IEEE Trans. Ind. Electron 62, 40-51 (2015) 